\title{
EVALUATION OF A RAILWAY BRIDGE USING DISTRIBUTED AND DISCRETE STRAIN SENSORS
}

\author{
C. Barker ${ }^{1}$, N.A. Hoult ${ }^{*}$, H. Le $e^{2}$ and V. Tolikonda ${ }^{3}$ \\ ${ }^{I}$ Department of Civil Engineering, Queen's University, Kingston, Canada \\ ${ }^{2}$ CN Railway, Edmonton, Canada \\ ${ }^{3}$ CN Railway, Homewood, USA \\ * Corresponding author
}

\begin{abstract}
With over 100,000 rail bridges in North America, of which many are over 100 years old, railway corporations are interested in developing ever more effective condition assessment and monitoring strategies for their structures. In general, strain gauges have been a common and reliable sensing tool as they can provide low-noise measurements at high sampling frequencies (greater than $100 \mathrm{~Hz}$ ). However, fully distributed sensors, in the form of fibre optics strain sensors, have the potential to compliment discrete sensors by providing a more complete understanding of structural behaviour under loading. In this paper, a sensor system including fibre optics sensors on the rail and strain gauges on the rail and bridge members was used to measure the strain experienced during train passage on the Newmarket Bridge, located in North Bay, Canada. The test span is a typical open deck through plate girder (TPG) with a floor system consisting of stringers and floor beams. Four locations on the continuously welded rail, an intermediate floor beam supporting two bays, the bottom lateral bracing system in two bays as well as a $4 \mathrm{~m}$ length of rail were instrumented with strain gauges and fibre optic sensors. The research objectives were to (i) understand the load path from wheel to rail to bridge and (ii) quantify the stress states of the instrumented bridge members under service traffic. Conclusions drawn from this research will assist the assessment of railway bridge behaviour and improve future monitoring and reinforcement techniques.
\end{abstract}

\section{Notation}

DFOS - Distributed Fibre Optic Sensor

TPG - Through Plate Girder

\section{Introduction}

Many railroad bridges in North America were designed and constructed over 100 years ago. For example, in North America, the US Department of Transportation reports that more than half of the 100,000 railroad bridges were built before 1920 (AREMA, 2003). And while the bridge stock is getting older, the average tonnage hauled by freight train has more than doubled during that time (Weatherford et al., 2008). As a result, the capacities of some older bridges are being exceeded (Unsworth, 2010).

One potential issue for older bridge structures is their ability to transfer and resist longitudinal forces due to braking and accelerating trains (Unsworth, 2010). Here again, older bridges were not designed for the heavier and more powerful trains that are now in service (Weatherford et al., 2008) and as a result conservative assumptions have to be made when assessing these structures when estimating the forces in each member. The current solution to this problem is to install traction bracing at a cost between $\$ 100,000$ and $\$ 300,000$ per span. However, due to a lack of quantitative data about the forces involved, it is not clear whether this rehabilitation technique is the optimum solution.
Currently, industry practice is to conduct periodic visual inspections for the maintenance and assessment of railroad bridges (AREMA, 2015). However, visual inspections can be highly subjective (Graybeal et al., 2002). And while they can provide quantitative data about physical parameters, they do not provide the engineer in charge of assessing the bridge with the quantitative data about forces in members they often require to determine if the bridge has the necessary structural capacity.

Structural monitoring has the potential to provide the required quantitative data to assess these potentially critical bridges. The research objectives were to (i) understand the load path from wheel to rail to bridge and (ii) quantify the stress states of the instrumented bridge members under service traffic. The next section contains background information about traction forces and rail monitoring techniques. The bridge site and instrumentation plan will then be introduced followed by a presentation and discussion of the results of monitoring of the bridge. Conclusions will then be drawn.

\section{Background}

\subsection{Traction forces on rail bridges}

Rolling friction caused by local deformations at the wheel-rail interface generate longitudinal forces in the rail under the action of locomotive braking and acceleration (Unsworth, 2010). While numerical methods, considering dynamic equilibrium of the system, exist for estimating the magnitude of such forces, considerable effort has reduced this calculation 
to a function of the loaded length of the bridge under consideration (AREMA, 2003). A more complex problem, deserving of further consideration, is the determination of the exact load path and distribution of these longitudinal forces throughout the bridge, which is highly variable, and largely dependent on the bridge arrangement, bearing details, and substructure (Unworth, 2010). Thus, monitoring of in-service rail bridges is essential to verify or improve the current mathematical solutions that exist for modelling the magnitude and transfer path of tractive forces.

\subsection{Rail monitoring using strain gauges}

Past studies aimed at evaluating the performance of rail bridges commonly measure strain through the use of discrete electrical resistance gauges. One study, conducted by Srinivas et al. (2011), bonded strain gauges to the rail and girders of a steel bridge in India. The study concluded that roughly one third of the axial force induced in the rail is transferred to the supporting girders under train passage, and the magnitude of the stresses developed fell conservatively within the design limits imposed by the Indian Railways (Srinivas et al., 2011). Another study by Foutch et al. (2006) applied strain gauges to the rail and members of a steel truss bridge in Texas. Results indicated that the bridge experienced the greatest longitudinal force under the action of an air braking test (Foutch et al., 2006). While proven as a reliable and accurate sensing tool, the discrete nature, difficulty of field application, and poor longterm durability of strain gauges limit their usefulness for field applications in rail bridge monitoring.

\subsection{Rail monitoring using distributed strain sensors}

A potentially useful sensor alternative to strain gauges, for use in the field monitoring of rail bridges, are the distributed fibre optic strain sensors. Recently, such technology has been used with success in a variety of rail applications. For example, Wheeler et al. (2018) bonded 15 meters of a nylon-coated fibre to the head and foot of a rail in Kingston, Canada and measured dynamic strains under the passing of a hi-rail vehicle and a passenger train. General visual agreement between fibre optic strain results and digital image correlation confirmed that distributed sensing could accurately capture dynamic strains, when vibration effects were minimized at slower train speeds (Wheeler et al., 2018). In another study by Wheeler et al. (2019) similar technology was used on a section of track, which successfully measured distributed strains along a $7.5 \mathrm{~m}$ section of track, allowing for rail seat forces to be calculated under a moving train (Wheeler et al., 2019).

A study by Van Der Kooi et al. (2018) involved bonding 20 meters of optical fibres to the top and bottom chords of one span of an 8 span steel truss bridge, located in Jordan, Ontario, Canada. The instrumented span was subjected to three loading cases, included static loading of a work train, dynamic loading of a work train and the dynamic loading of an in-service train. Results from static measurements indicated that distributed strains could be accurately measured by the fibre optic system and used to detect bending moments in the members instrumented (Van Der Kooi et al., 2018). However, as indicated by the previously mentioned study from Wheeler et al. (2018), a degradation in the quality of measured strain occurred at higher train speeds due to vibrational effects.

\section{Experimental campaign}

\subsection{Bridge}

The Newmarket Bridge is a four span, single-track, open deck steel plate girder bridge located near North Bay, Canada (4616'6.66"N 79²3'33.70” W). The bridge was constructed in 1912 and is comprised of three deck plate girder spans crossing the Lavase River, and a single through plate girder (TPG) span, passing over a Canadian Pacific Railway track. Each deck plate girder span measures roughly 23 meters in length, approximately 2.75 meters in depth and is simply supported with an expansion joint at its north end and a fixed joint at its south end, all resting upon a series of reinforced concrete piers.

For this study, the single 37 meter TPG span at the north end of the bridge was the subject of monitoring, as seen in Figure 1. There is a lateral force bracing system under the TPG that is divided into 8 bays, 7 of which being evenly spaced at 5.53 meters on centre, and the remaining bay on the south end being skewed in order to conform to the orientation of the pier it rests upon, as seen in Figure 2. Each bay consists of two built-up floor beams connected at their webs by two W610 $\times 120$ and two W610 $\times 171$ stringers running parallel to the track and on which 14 evenly spaced wooden ties are connected via steel hook bolts. The stringers are braced laterally to one another at the midspan of each bay by a series of built-up I-beams. Lastly, each bay contains a pair of $\mathrm{L} 152 \times 89 \times 13$ cross braces, which are connected at the bay corners to the plate girders and floor beams by gusset plates. The plate girders of this span measure approximately 3 meters in depth with stiffener plates spaced every 1.5 to 2 meters. The $115 \mathrm{lbs}$ RE continuously welded rail is centrally located over the bridge and has a gauge (rail to rail) spacing of 0.823 meters. In similar fashion to the three other spans, the support conditions of the through plate girder span include an expansion joint at its north end and a fixed joint at its south end. The monitoring described in this paper represents the first, of two, rounds of planned tests. The second will follow the installation of traction bracing at the north end of this span in order to investigate the effects of such reinforcement.

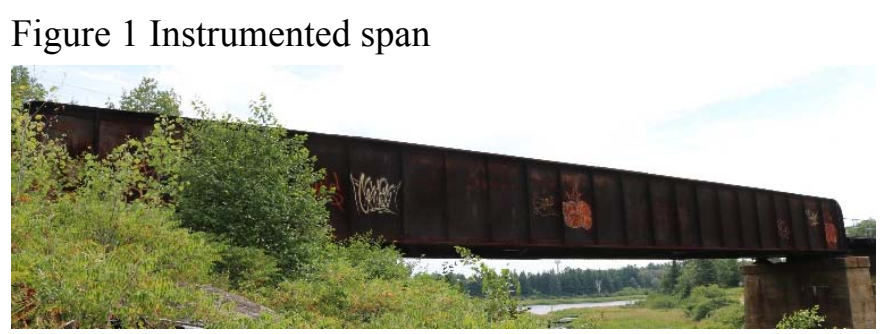

\subsection{Instrumentation}

Figure 2 illustrates the instrumentation layout executed for this experimental campaign. 
Figure 2 Instrumentation layout (not to scale)

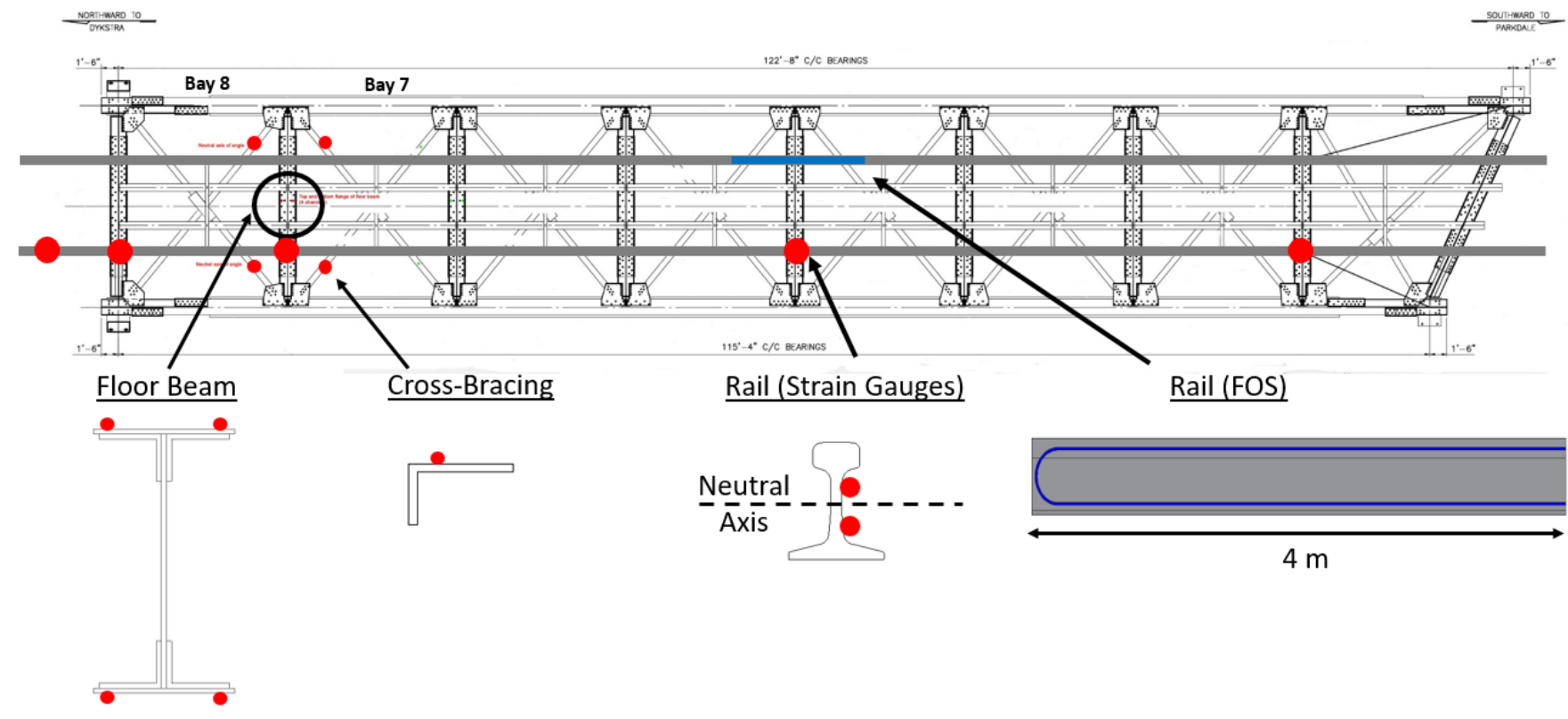

The rail was instrumented with both fibre optic sensors and strain gauges at midspan to evaluate the correlation between measured results, see Figure 3. A nylon-coated fibre with an $8.2 \mu \mathrm{m}$ diameter core was bonded using a cyanoacrylate adhesive (Loctite 4861) to the head and foot of the rail, at a height of $25 \mathrm{~mm}$ and $140 \mathrm{~mm}$ above the rail's base. Prior to bonding, the rail surface was cleaned using water and a degreasing agent. Finally, the fibre was coated in silicone to protect it for long-term use, as seen in Figure 3.

Figure 3 Fibre optic sensors on rail

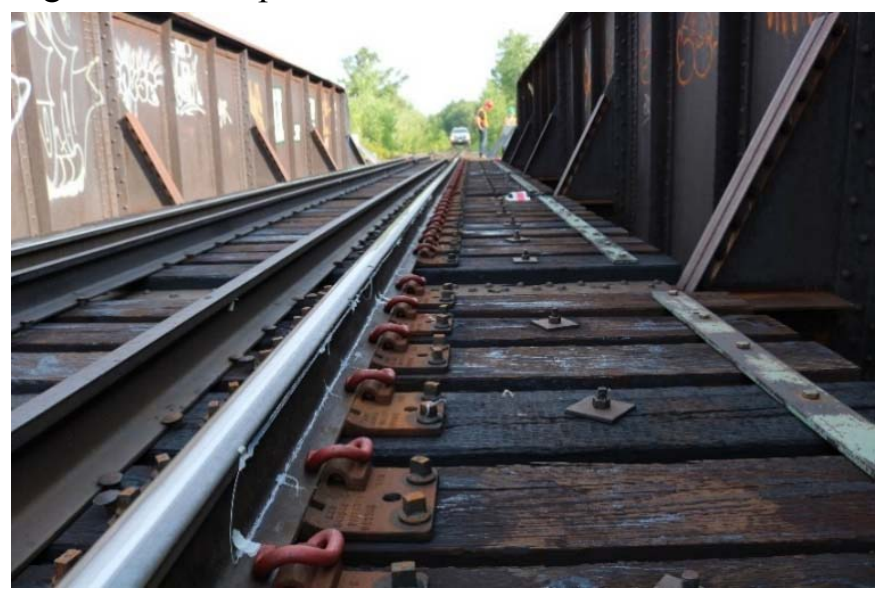

Strain gauges were bonded to the rail at three locations on the bridge and one location at $2.13 \mathrm{~m}$ off the bridge in order to determine a distribution of longitudinal rail force and to detect the extent to which this force was being transferred between the bridge and the connecting track. In a similar orientation to the fibre optic layout, see Figure 3, the strain gauges were bonded above and below the neutral axis of the rail, at heights of $57 \mathrm{~mm}$ and $95 \mathrm{~mm}$ above the rail base, as shown in Figure
4. This allows for the calculation of curvature and subsequently the derivation of axial stress at each sensor location. The strain gauges were installed by first grinding the rust off the steel and then applying the gauge to the chemically cleaned surface with a bonding adhesive, before soldering the lead wires to the terminal pads of the gauge.

Figure 4 Strain gauges on the rail over top of floor beam

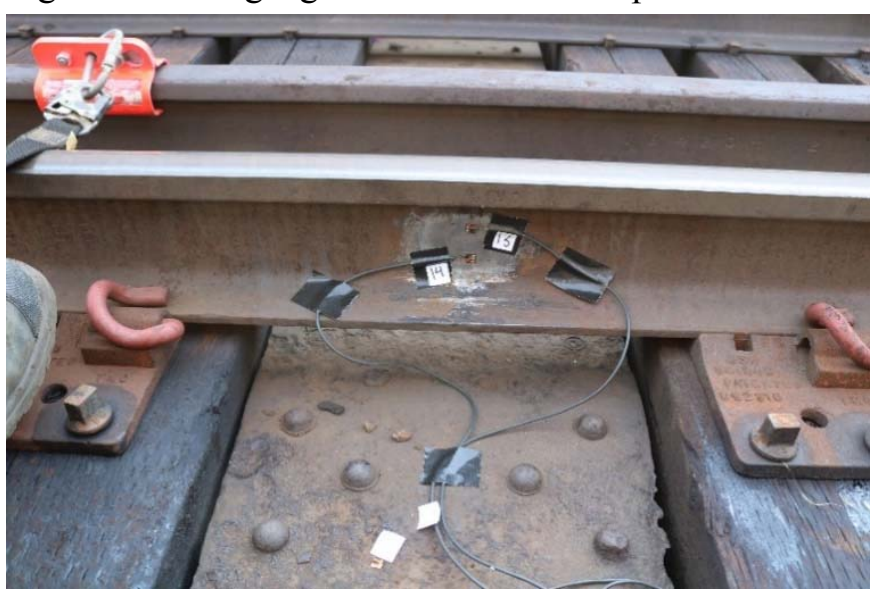

In order to study the complex longitudinal force transfer mechanism between the rail and underlying bridge members, a series of strain gauges were bonded to the floor beam and cross braces located directly under the rail instrumented with gauges at the north end of the bridge, as indicated in Figure 2. Four gauges were bonded towards the extreme edges of the top and bottom flange at the midspan of the floor beam, in order to capture in-plane and out-of-plane bending strains, as shown in Figure 5. 
Figure 5 Strain gauges on the floor beam's bottom flange

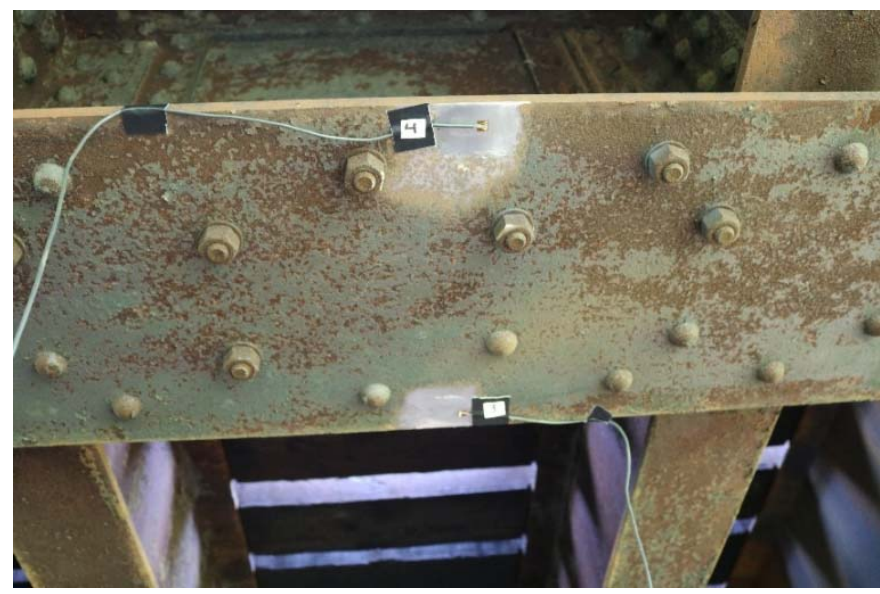

Distributed strains measured by the fibre optic sensor were captured using the LUNA Innovations ODiSI-B dynamic analyser, which uses a sensor spacing of $2.61 \mathrm{~mm}$ and gauge length of $5.22 \mathrm{~mm}$ when used in conjunction with a sensing range of $20 \mathrm{~m}$ and a sampling frequency of $50 \mathrm{~Hz}$ (Luna Innovations, 2017).

\subsection{Loading}

Three types of tests were conducted using full in-service freight trains. For the first type of test, the train passed over the bridge at a constant velocity, in order to represent typical service conditions and to gather baseline measurements. The second was an acceleration test in which the locomotive was instructed to approach the bridge at a velocity under $16 \mathrm{~km} / \mathrm{h}$ and then to begin accelerating once the midspan of the TPG span was reached. The intention of this test was to measure longitudinal forces generated by the tractive effort of the locomotives. Finally, in an attempt to measure dynamic braking forces, in the third test the locomotive approached the bridge at a velocity under $16 \mathrm{~km} / \mathrm{h}$ and then engaged its brakes upon reaching the midspan of the TPG span. This upper speed limit was imposed to reduce the negative influence of vibration on the data. Once the locomotives had cleared the instrumented span, they were free to accelerate and thus the remainder of the train in both the accelerating and braking tests was actually accelerating across the span.

The dynamic fibre optic analyser started recording strain as soon as the locomotive approached within approximately 10 meters of the bridge and was stopped only once the entire freight train had cleared the bridge. The strain gauges were automatically triggered to record once the incoming train caused a user-specified amount of strain in the gauges. The system automatically recorded at least 10 seconds of pretrigger data, in order to capture the strain before the train is actually on the span, and stopped recording once at least 10 seconds had passed after the event returned the gauges to their initial state of strain.

\section{Results and Discussion}

\subsection{Rail strains during the acceleration test}

Figure 6 shows the strain measured by both the fibre optic sensor and the strain gauges as two axles accelerated past the midspan of the TPG, heading northbound. The data from the fibre bonded above the neutral axis of the rail (top fibre) and below the neutral axis of the rail (bottom fibre) are presented with respect to their location on the rail, in which 8 total meters of fibre was bonded above and below the neutral axis of a 4 meter segment of rail. In order to improve the visual appearance of the fibre optic data, a cut-off filter was used to remove noise due to vibrational effects followed by a linear interpolation between remaining data points. It is important to note that the strain gauges, whose data is presented in Figure 6 , were bonded to the rail next to the one with the fibre but at the midspan of the bonded fibre length. Additionally, the strain gauges were not bonded at the same height along the rail that the optical fibres were, so the measurements have been extrapolated to what they would be at the fibre optic height, assuming plane sections remain plane, in order to visually assess their correlation. While Figure 6 depicts a single point in time where two axles of a locomotive bogie were directly over the fibre, dynamic strain was recorded for the entire event. In this case, the direction of the wheel's motion would be from left to right when looking at Figure 6.

\section{Figure 6 Strain gauge and DFOS strain measurements}

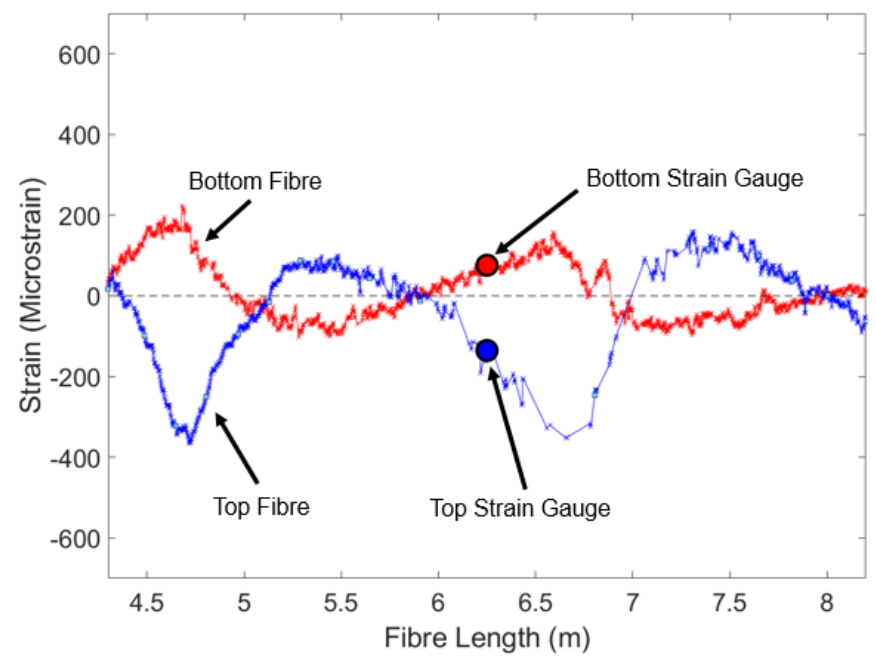

As expected, axle loads cause positive bending directly at wheel locations, and negative bending between wheels. This indicates that rail behavior under the passage of a train is primarily dominated by bending, rather than axial forces. Figure 6 also demonstrates the significant advantage that distributed strain sensors have over traditional strain gauges. The fibre optic sensors provide a more comprehensive understanding of structural behaviour over discrete sensor technologies while offering similar accuracy to strain gauges, as demonstrated here by the good visual agreement of the data. It is, however, important to note that the top strain gauge measurements deviated from the fibre optic measurements when the wheels were directly above the strain gauges, possibly to the effect of localized stress concentrations at the wheel-rail interface. 


\subsection{Rail axial force during the acceleration test}

Figure 7 shows the distribution of axial force generated in the rail at the same moment in time as depicted in Figure 6. Since strain was measured at two points along the height of the rail at each sensor location, curvature could be calculated and used, through interpolation, to determine the strain at the neutral axis of the rail, which was established from the geometric and material properties of the section. Multiplying this axial strain by the rail's cross-sectional area $\left(7236.8 \mathrm{~mm}^{2}\right)$ and elastic modulus (assumed to be 207,000 MPa) results in the axial force distribution shown in Figure 7.

Figure 7 Axial rail force from strain gauges and DFOS

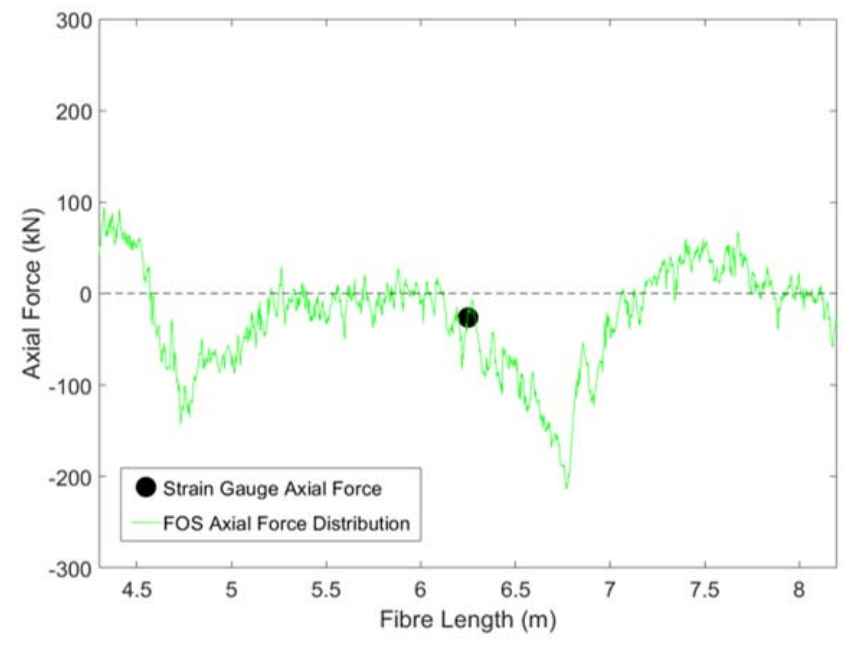

Figure 7 again demonstrates the good visual agreement between fibre optic and strain gauge data while showing the advantage that distributed sensors have over traditional, discrete sensors in aiding with the understanding of overall structural behaviour. It is clear from Figure 7 that the axial force distribution from locomotive loading is not constant, but rather has local maximums of compression at wheel locations that then transition to zero force between wheels and a tensile force between adjacent bogies. This may be indicative of a high connection stiffness between the rail and the girder, according to models put forth by Srinivas et al. (2011) that propose a similar axial force distribution in rails whereby this force is quickly dissipated from the rail into the bridge superstructure.

\subsection{Stress in the floor beam during the acceleration test}

Since the intermediate floor beam was instrumented with four strain gauges bonded on the outer surface and at the extreme edges, 4 points of strain could be measured at a single crosssection of the beam, allowing a plane of stress at the midspan of the beam to be determined. Figure 8 was created using this data in order to visualize the bending stresses experienced by the floor beam under the passage of a train. The I-beam section in the figure represents the nominal dimensions of the actual floor beam's cross section. Each value of stress (calculated using the measured strain multiplied by the modulus of elasticity) was then plotted at the exact location on this crosssection where the strain gauges were bonded. A two dimensional plane connecting each point of calculated stress and extending to the extreme edges of the cross-section was then produced to aid in the visualization of the floor beam's complex stress state.

Figure 8 specifically depicts a plane of stress corresponding to a single point in time during an acceleration test in which a locomotive axle was positioned directly over the floor beam. It is important to note that the floor beams are perpendicular to the rails and that, for this specific test, the train was moving in the direction indicated in Figure 8.

Figure 8 Biaxial bending in floor beam

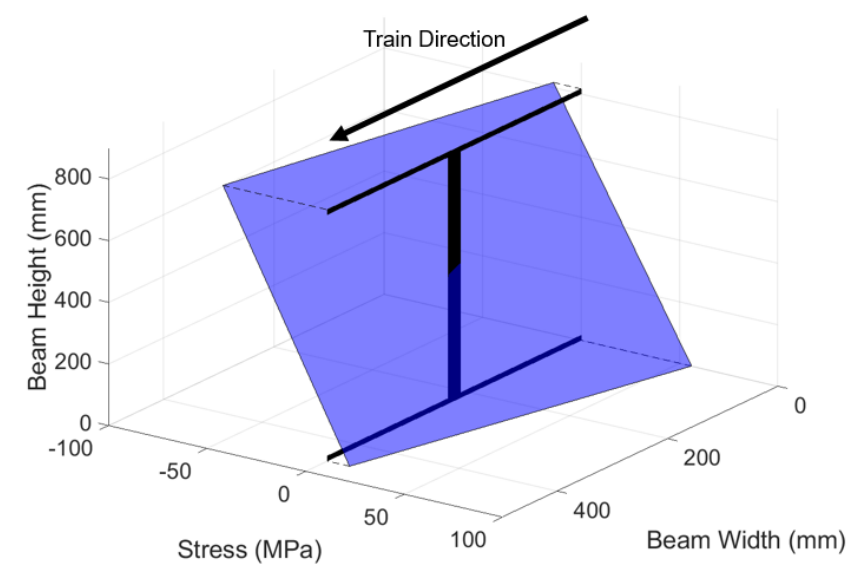

As evident by the skewed orientation of the stress plane, the floor beam experiences a state of bi-axial bending at the point in time presented. In this instance, the bending in the out-ofplane direction is opposite to the direction of the train motion. That is, the beam is going into compression on the left side of the cross-section in Figure 8 and tension on the right side of the cross-section. The weight of the train is causing the beam to bend downwards, as expected, causing compression in the top of the beam and tension in the bottom. As a result, the maximum compressive stress (approximately $60 \mathrm{MPa}$ ), due to both in-plane and out-of-plane bending, occurs in the top left corner of the cross-section in Figure 8 while the maximum tensile stress (again approximately $60 \mathrm{MPa}$ ) occurs in the lower right corner.

\subsection{Force transfer during the acceleration test}

In an attempt to better understand the force transfer mechanism, strain gauges were positioned to be centrally located around the intermediate floor beam between bays 7 and 8 of the TPG span. The complete force transfer sensor layout included two strain gauges on the rail positioned directly over the floor beam, four gauges on the floor beam, in the orientation described previously, and one gauge on each of the four adjacent cross braces, bonded in-line with the vertical centroid of the angle. Again, this sensor layout is illustrated in Figure 2.

To study the force transfer mechanism in this bridge under the passage of a train Figure 9 presents data for an entire acceleration test, in which a freight train heading northbound under $16 \mathrm{~km} / \mathrm{hr}$ accelerated once its front-most engine reached 
the through plate girder's midspan. Figure 9(a) shows the axial force generated in the rail at the location of the strain gauges, (b) shows the maximum weak-axis stresses in the floor beam at its midspan, and (c) shows the stresses in bay 7 and 8's cross braces at the location of the bonded strain gauge. Rail companies, like CN Railway, are particularly interested in the amount of out-of-plane stresses experienced by the floor beams and thus, these have been presented in Figure 9, rather than total bending stresses.

Since the train was heading northbound on the bridge for the data shown in Figure 9, it must pass all three simply supported deck plate girder spans before reaching the instrumented TPG span. At approximately 12 seconds, the floor beam and cross braces begin measuring strain, indicating the point in time when the train's front-most axle makes contact with this span. From this point on, each jump in stress, illustrated in Figures 9(b) and (c), correspond to an axle passing directly over the instrumented intermediate floor beam. Finally, the data indicates that the full train clears the bridge at approximately 106 seconds because of the close proximity of this floor beam to the end of the bridge.

Figure 9(a) shows that the passage of the accelerating northbound train induces a tensile force in the rail that gradually increases until the train completely clears the bridge, at which point the rail experiences a maximum force of approximately $80 \mathrm{kN}$. It is possible that this maximum only occurs once the train has cleared the bridge due to permanent movement of the rail, observed previously on mainline track by Murray et al. (2015). Design equations put forth by Unsworth (2010) suggest that the fully loaded through plate girder span should be designed to accommodate $25 \sqrt{\mathrm{L}}$ kips of longitudinal force, where $\mathrm{L}$ is the length of the loaded span in feet which, equals a total force of approximately $1134 \mathrm{kN}$ for this span, or $567 \mathrm{kN}$ per rail, considering a fully loaded span. The measured axial force at one discrete location in the rail under train passage is approximately $15 \%$ of the suggested design load and therefore far below the capacity of the bridge, were it designed in accordance with Unsworth's equations (2010).

The tensile behaviour exhibited by the rail is logical, if one considers the model for a rolling mass on a simply supported span, presented by Unsworth (2010). In this model, a train moving away from a fixed joint and towards an expansion joint would generate an axial force in the rail acting towards the expansion joint and thus extending the simply supported span axially. This theory is consistent with the results obtained, which indicate that the rail is in an increasing state of tensile stress under the passage of a train moving towards the expansion joint at the north end of the bridge. The results presented appear to demonstrate that the axial movement of the rail conforms to movement of the bridge, which is dependent upon the bearing details of the span. Under similar logic, a train moving away from the expansion joint and towards the fixed joint should put the rail in a state of axial compression, which is also consistent with the collected data.

Figure 9 Force transfer between elements: (a) shows axial force in the rail at the intermediate floor beam location, (b) shows the weak axis bending stresses in the floor beam and (c) includes the stresses in the cross braces

(a)

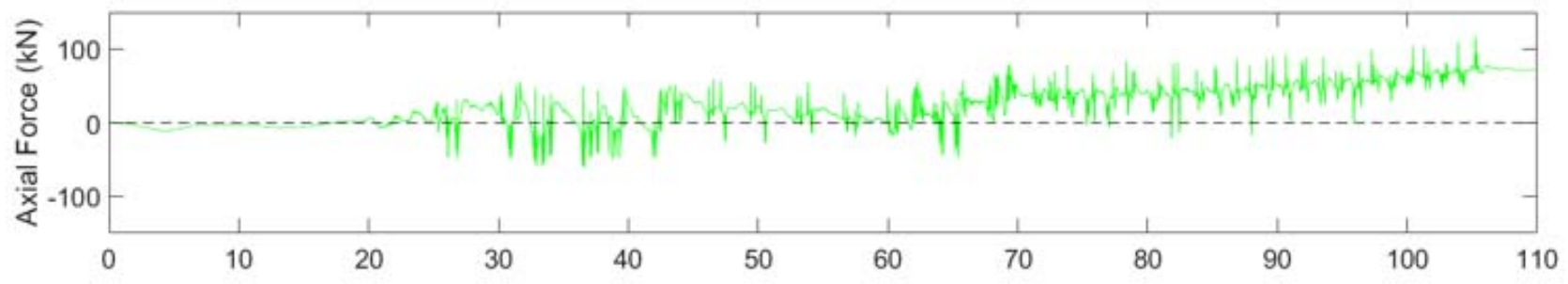

(b)

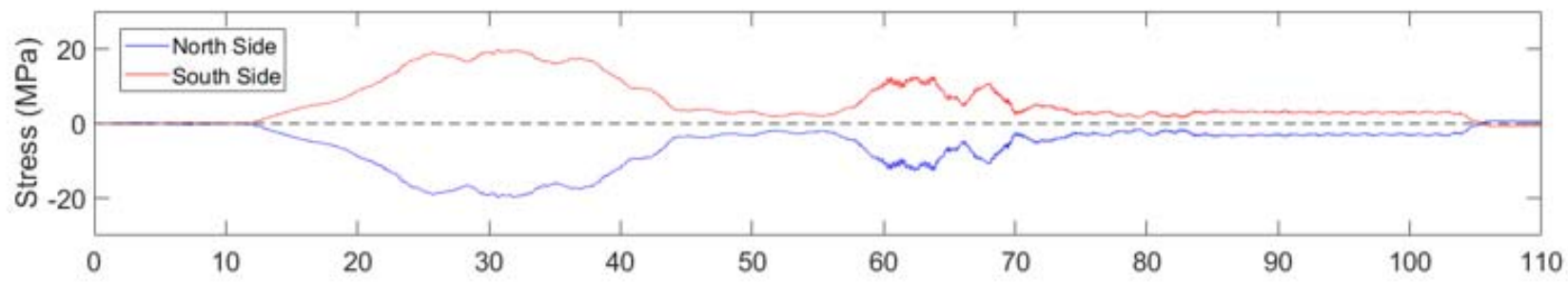

(c)

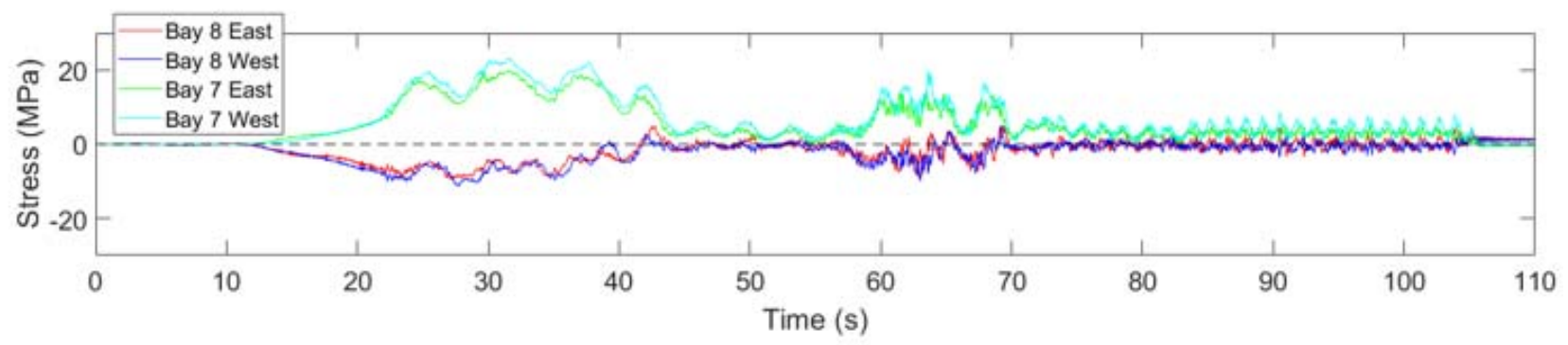


Figure 9(b) shows the pure out-of-plane bending stresses experienced by the intermediate floor beam. By comparing Figures 9(a) and 9(b), the correlation between axial forces in the rail and stresses in the floor beam is not obvious. Further investigation and verification of the out-of-plane behaviour of the floor beams will require the development of a finite element model. However, it is worth noting at this time that the stresses presented are less than the yield stress of steel commonly used for Canadian riveted bridges during the time period when the bridge was built, that being between 190 and $225 \mathrm{MPa}$ (CISC, 2016). However, these stresses do not include those from the self-weight of the structure itself and thus do not represent the total stress state.

Visual comparison between Figures 9(b) and (c) indicate a pattern where the response of these members is of similar shape but different magnitude. In terms of magnitude, the cross braces in bay 7 experience roughly double the stress as those in bay 8 . The reason for this is not clear as the loading in the cross bracing in each bay should be similar. This behaviour will also be investigated in greater depth with a finite element model.

\section{Conclusions}

A steel girder rail bridge, in North Bay, Canada, was instrumented with distributed and discrete sensors to evaluate the stress levels in the rail and various members of the bridge during the passage freight trains and to study the tractive and braking force transfer mechanism imposed by the acceleration and braking of engines on the bridge. A single through plate girder span was monitored, and was instrumented with 8 meters of fibre optic cable on the rail at midspan, a pair of strain gauges at four locations on the rail, four strain gauges on an intermediate floor beam and one strain gauge on each of four cross braces. Three types of tests were conducted in which freight trains were instructed to pass over the TPG span at a constant velocity, accelerate after reaching midspan and to brake after reaching midspan.

Major conclusions from the experimental campaign include:

- Bending is the dominant behaviour in a rail under the passage of a train, whereby local maximums of positive bending occur at axle locations and local maximums of negative bending occur between axles.

- The axial force distribution in a rail demonstrates spikes in compressive force at axle locations which appear to dissipate immediately into the superstructure of the bridge.

- Distributed fibre optic sensors generally show good visual agreement with discrete strain gauge data.

- The correlation between stresses in the rail, floor beams and cross braces is not obvious and requires further investigation.

\section{Acknowledgements}

The authors would like to acknowledge the financial support of the Natural Sciences and Engineering Research Council of Canada. The authors also gratefully acknowledge the assistance of Jefferey Jones of CN Rail as well as Simon Howell and Jacob Yager of Queen's University.

\section{References}

AREMA (American Railway Engineering and Maintenanceof-way Association) (2003) Practical Guide to Railway Engineering. AREMA, Lanham, Maryland, USA.

Weatherford BA et al. (2008) The State of U.S. Railroads, a Review of Capacity and Performance Data. RAND Corporation, Santa Monica, CA, USA.

Unsworth JF (2010) Design of Modern Steel Railway Bridges. CRC Press, Boca Raton, FL., USA.

AREMA (2015) 2015 Manual for Railway Engineering, Chapter 15. AREMA, Lanham, Maryland, USA.

Graybeal et al. (2002) Visual Inspection of Highway Bridges. Journal of Nondestructive Evaluation 21(3): 67-83, 10.1023/A:1022508121821.

Srinivas V et al. (2011) Evaluation of Longitudinal Force on a Railway Bridge Based on Strain Measurements. Experimental Techniques 37(1): 618-625, $\quad 10.1111 / \mathrm{j} .1747-$ 1567.2011.00747.x.

Foutch DA et al. (2006) Investigation of Longitudinal Forces in a Concrete Railroad Trestle. Journal of Bridge Engineering 11(5): 618-625, 10.1061/(ASCE)1084-0702.

Wheeler et al. (2018) Measurement of distributed dynamic rail strains using a Rayleigh backscatter based fiber optic sensor: Lab and field evaluation. Transportation Geotechnics 14(1): 70-80, 10.1016/j.trgeo.2017.10.002.

Wheeler et al. (2019) Use of fiber optic sensing to measure distributed rail strains and determine rail seat forces under a moving train. Canadian Geotechnical Journal 56(1): 1-13, 10.1139/cgi-2017-0163.

Van Der Kooi et al. (2018) Monitoring an In-Service Railway Bridge with a Distributed Fiber Optic Strain Sensing System. Journal of Bridge Engineering 23(1): 05018007, 10.1061/(ASCE)BE.1943-5592.0001281.

Luna Innovations (2017) ODiSI-B Users Guide. https://unainc.com/wp-content/uploads/2014/05/ODiSI-B-

Users-Guide.pdf (accessed 01/08/2019).

Murray et al. (2015) Measurement of Vertical and Longitudinal Rail Displacements using Digital Image Correlation. Canadian Geotechnical Journal 52(2): 141-155, 10.1139/cgi-2013-0403.

CISC (Canadian Institute of Steel Construction) (2016) Handbook of Steel Construction. 11 ${ }^{\text {th }}$ Edition, Part 6 Properties and Dimensions. CISC, Markham, ON, Canada. 